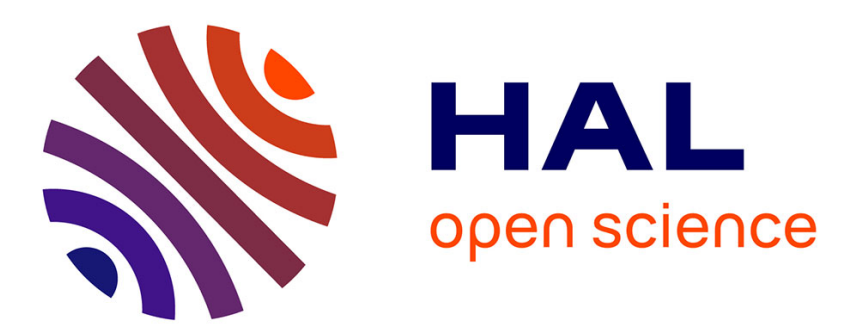

\title{
Crossed views of burden and emotional distress of cancer patients and family caregivers during palliative care
}

\author{
Tanguy Leroy, Emmanuelle Fournier, Nicolas Penel, Véronique Christophe
}

\section{To cite this version:}

Tanguy Leroy, Emmanuelle Fournier, Nicolas Penel, Véronique Christophe. Crossed views of burden and emotional distress of cancer patients and family caregivers during palliative care. PsychoOncology, 2016, 24 (25), pp.1545 - 1285. 10.1002/pon.4056 . hal-01424857

\section{HAL Id: hal-01424857 \\ https://hal.science/hal-01424857}

Submitted on 3 Jan 2017

HAL is a multi-disciplinary open access archive for the deposit and dissemination of scientific research documents, whether they are published or not. The documents may come from teaching and research institutions in France or abroad, or from public or private research centers.
L'archive ouverte pluridisciplinaire HAL, est destinée au dépôt et à la diffusion de documents scientifiques de niveau recherche, publiés ou non, émanant des établissements d'enseignement et de recherche français ou étrangers, des laboratoires publics ou privés. 
Psycho-Oncology, 25: 1278-1285 (2016)

Running Head: Crossed views of burden and emotional distress in palliative care

\title{
Crossed views of burden and emotional distress of cancer patients and family caregivers during palliative care
}

\author{
Tanguy Leroy ${ }^{1,2}$, Emmanuelle Fournier ${ }^{2}$, \\ Nicolas Penel ${ }^{3,4} \&$ Véronique Christophe ${ }^{2,5}$
}

\begin{abstract}
Affiliations:
${ }^{1}$ Université Lumière Lyon 2, Social Psychology Research Group (GRePS EA 4163), Bron, France

${ }^{2}$ Université de Lille, UDL3, SCALAB UMR CNRS 9193, Villeneuve d'Ascq, France

${ }^{3}$ Centre Oscar Lambret, Department of General Oncology, Lille, France

${ }^{4}$ Université de Lille, UDL2, EA 2694 Public Health: Epidemiology and Quality of Care, Lille, France ${ }^{5}$ SIRIC ONCOLille, Lille, France
\end{abstract}

\section{Correspondence:}

Postal address: $\quad$ Université Lumière Lyon 2 - Institut de Psychologie

Groupe de Recherche en Psychologie Sociale (GRePS EA 4163)

5 avenue Pierre Mendès-France

69676 Bron (France)

E-mail: tanguy.leroy@univ-lyon2.fr

Tel: +33478 772357 


\begin{abstract}
Objective. Studies regarding natural caregivers' burden (CB) in palliative situations, as well as its determinants and consequences, have been numerous during the last twenty years. Yet, studies regarding how terminally-ill cancer patients perceive their caregivers' burden (selfperceived burden, SPB) are less common. This study aims to assess the links between CB and SPB evaluated by means of the very same items. It also aims at identifying the determinants of potential differences between CB and SPB and their consequences on emotional distress among both members of the dyad.

Methods. Sixty cancer patients from a palliative care unit and their principal natural caregiver completed questionnaires concerning the subjective burden of the caregiver, their own personal emotional distress and that of the other member of the dyad.

Results. Globally, patients had a good perception of their caregivers' burden, although a little overestimated, except for their difficulties in managing their time. Caregivers overestimated patients' distress. The minimisation by patients of caregivers' burden was a source of emotional distress for the latter, and the perception of being a burden to others was a source of depression for patients. These results did not depend on the nature of the relationship between patients and their caregivers.

Conclusions. This data confirmed the need to study the experiences of the patient-caregiver dyad as well as their communication of their respective experiences, with a prospect to offer clinical interventions to optimise the quality of life and health of patients and their close relatives.
\end{abstract}

Keywords: cancer, oncology, caregiver burden, self-perceived burden, emotional distress, palliative care 


\section{Background}

Progress in oncology has prolonged the survival of patients suffering from advanced cancers while treatments are carried out primarily on an outpatient basis. As a consequence, family caregivers are called upon more and more, particularly at the end of patients' lives, without necessarily having the resources to do so [1-3]. This role of caregiver has well known consequences on the caregiver's life, physical and mental health, as well as marital and family relationships. Incidentally, when the patient needs help beyond the caregiver's time, financial, energy, emotional or social resources, the latter experiences a particular form of distress called "Caregiver Burden" (CB) [3-6]. Studies dealing with the evaluation of CB and the identification of its determinants show that $\mathrm{CB}$ depends on the patient's characteristics and their pathology, the caregiver themselves, and the relationship between the caregiver and the patient [5]. They also show that CB is likely not only to change the caregiver's mental and physical health and their social relationships, but also to lower the quality of the assistance they can offer the patient, mainly because the burden impairs their perception of the patient's symptoms, experiences and quality of life [7].

Studies regarding how patients perceive their caregivers' burden are less common. The feeling of being a burden, called Self-Perceived Burden (SPB) [8] or perceived burdensomeness [9], has been linked to anxiety, depression, loss of dignity, hopelessness, guilt, impaired quality of life, and suicidal ideation [10-13]. Moreover, it may disrupt communication between patients and their families, and affect the decisions about their care, especially their treatment and its termination, or the place of death [11,14-16]. SPB affects a large proportion of patients at the end of their life (one to three terminally ill cancer patients in four according to studies), regardless of their culture, and whether or not they are taken care of in a palliative care unit $[10,12,17,18]$.

SPB may result from a patient's perception that the balance between their benefits (receiving support) and contributions (giving support) in the patient-caregiver dyad is uneven [19]. Thus, SPB and its deleterious consequences may increase when patients overestimate the cost or underestimate the benefits of their relationship for their caregivers. From the same point of view, caregivers may experience higher levels of $\mathrm{CB}$ and emotional distress when patients do not accurately estimate the cost of supporting them and, as a consequence, do not give their caregivers sufficient support (showing gratitude or reassurance, getting as autonomous as possible...). 
A few studies only assessed how accurately non-cancer patients perceive their caregiver's burden and how strongly SPB is actually linked to CB. These studies reported only weak to moderate correlations between SPB measured with the Self-Perceived Burden Scale [8] and CB assessed with different specific scales [20,21]. This recurring result suggests that the patients' sense of burdening others is founded on a perception of CB which is only partially accurate, and it incites to investigate further this lack of accuracy and identify its determinants and consequences.

However, using different scales to assess SPB and CB does not allow for addressing these issues. Therefore, the present study aims to assess, among terminally ill cancer patients and their natural caregivers, the differences between CB and SPB as measured with the exact same items, and to identify the factors involved in these differences as well as their consequences on emotional distress. Besides, as emotional distress is often a consequence of $\mathrm{CB}$ and SPB, an accurate perception of one's significant other's anxious or depressed symptoms constitutes an indirect indicator of the accuracy of burden perception. Therefore, this study also aims to assess how accurately each member of the patient-caregiver dyad perceives anxiety and depression in the other one.

It was thus hypothesized that (a) CB and SPB are moderately correlated, (b) CB and SPB are positively linked to anxiety and depression, (c) overestimation of CB by patients is positively linked to emotional distress among patients while negatively linked to it among caregivers, (d) like for burden, the accuracy of the perception of the other's emotional distress is moderate, (e) some characteristics of the individuals, the patient-caregiver relationship, the patients' health, and the family relationships account for misperceptions regarding burden and emotional distress.

\section{Methods}

\section{Participants}

From 2006 to 2008, 117 patients from a private non-profit hospital in northern France were offered to participate in this study. Inclusion criteria were as follows: consenting patients older than 18, with a histologically graded cancer, undergoing palliative care only, fluent in reading French, and naming a natural caregiver. Of these 117 patients, $20.5 \%$ refused to participate, and $28.2 \%$ could not name a natural caregiver who accepted to participate. Therefore, the analyses were carried out on 60 patient-caregiver dyads whose medical and 
sociodemographic characteristics are shown in Table 1. Patients who did not participate in the study did not significantly differ from participants on age, gender, or diagnosis. For $73.3 \%$ of the 60 participating patients, the decision to undergo palliative care had been made less than 30 days before participation in this study. Of the 60 participating caregivers, $65.0 \%$ were the patient's spouse, $25.0 \%$ were a son or daughter, $5.0 \%$ were a sister, and $5.0 \%$ were another family member (father or niece). There were 52 man-woman dyads and 8 woman-woman dyads.

Insert Table 1 about here

\section{Procedure and Ethics}

Patients were approached by a psychologist in charge of the study during one of their hospitalisations within the palliative care unit of the hospital. They were described the study, and interested patients were asked to sign an informed consent form and name, if possible, their significant other they considered to be their most important natural caregiver. The psychologist then approached the named caregiver on their next visit to the hospital and offered them to participate to the study. When the caregiver accepted, both members of the dyad were invited to complete separately a series of self-report anonymous questionnaires stamped with a shared ID number. Then, the questionnaires were returned to the psychologist who carried out a full debriefing of the participants. There was no monetary or other compensation given for participation.

The whole study was conducted in accordance with French regulations (authorisations DGS $n^{\circ}$ 2007-0002, CCTIRS $n^{\circ}$ 07.063, CNIL $n^{\circ}$ 907039) and was authorized by an empowered and independent Ethics Committee (CPP Nord-Ouest IV n ${ }^{\circ}$ 07/07).

\section{Measures}

Caregivers' burden was assessed with the validated French version of the Caregiver Reaction Assessment [22], a 24-item questionnaire measuring the positive impacts on selfesteem (ESTEEM), problems in organising and managing time (TIME), lack of family support (SUPPORT), health deterioration (HEALTH), and financial problems (MONEY). We chose this questionnaire to assess burden as it includes a positive dimension, which makes it more comprehensive and acceptable for participants. This measure has been found to have very good psychometric properties among family caregivers of palliative care cancer patients [23]. In the present study the CRA subscales had acceptable Cronbach's alphas (.64 to .90 among caregivers and .65 to .84 among patients). An average score ranging from 1 to 5 was 
calculated for each dimension: the higher this score, the greater the impact on the caregiver's life. This scale was self-reported by caregivers (assessment of $\mathrm{CB}$ ) and proxy-reported by patients (assessment of SPB).

Emotional distress was assessed with the validated French version of the very common Hospital Anxiety and Depression Scale [24]. Two scores ranging from 0 to 21 were computed (one for anxiety, the other for depression): the higher these scores, the more emotionally distressed the individual, with 8 representing the cut-off of sensitivity. This scale was both self-reported and proxy-reported by the patient and the caregiver so that we could measure a patient's emotional distress and its perception by the caregiver as well as a caregiver's emotional distress and its perception by the patient.

The quality of family relationships was assessed with the validated French version of the Family Relationship Index, a short version of the Family Environment Scale [25]. It measures cohesion (COHESION), expressiveness (EXPRESSION) and conflict (CONFLICT) among families. This scale was self-reported by both the patient and their caregiver, then their scores were averaged so that every dyad got only one score (ranging from 0 to 7 ) for each of the three dimensions: the higher this score, the more cohesive, expressive, or conflictual, the family.

Patient's health was assessed by the doctor using the Karfnofsky Performance Scale [26]. The existence of home hospitalisation was also recorded (HOME HOSPITALISATION: 1 = YES, $0=\mathrm{NO})$.

Patient's autonomy was assessed by the doctor using the Functional Independence Measure [27]. The patient gets a total score (AUTONOMY) ranging from 18 to 126: the higher this score, the more functionally independent the patient.

Sociodemographic data were also recorded, including whether the caregiver is the spouse of the patient (SPOUSES: 1 = YES, $0=$ NO), their age (PATIENT'S AGE and CAREGIVER'S AGE; AGE DIFFERENCE = PATIENT'S AGE - CAREGIVER'S AGE), their gender (PATIENT'S GENDER and CAREGIVER'S GENDER: 1 = MALE, 0 = FEMALE; GENDER DIFFERENCE $=$ PATIENT'S GENDER CAREGIVER's GENDER), whether the two members of the dyad are religious (PATIENT'S RELIGIOSITY and CAREGIVER'S RELIGIOSITY: $1=$ YES, $0=$ NO), their educational level (PATIENT'S EDUCATION and CAREgIVER's EDUCATION scored from 1 to 5), and whether the caregiver works (WORKING CAREGIVER: $1=$ YES, $0=$ NO).

\section{Data analysis}

This study involved assessing links between predictive factors and outcomes. First, all predictors were mean-centred variables. We then assessed structural equation models using 
AMOS 20. This method presents several benefits compared to classic multiple regressions, including a reduced risk of overestimation of regression coefficients and explained variances, as well as taking account of the significant or hypothesised correlations between predictive factors. In all these models, the only hypothesised paths between predictive factors and outcomes were those for which bivariate correlations were significant at the usual .20 level. A few values were missing, therefore the incomplete data set was analysed using maximum likelihood estimations of this missing data. Moreover, the maximum likelihood extraction method was applied to the analyses of the covariance matrices. The quality of fit of these models was assessed using recommended fit indices including $\chi^{2}, S R M R, R M S E A, C F I$, and $T L I$ [28]. An excellent model fit is demonstrated by a non-significant $\chi^{2}$ but a $\chi^{2} / d f$ lower than 2 is generally considered an indicator of a good fit [29]. Moreover, SRMR and RMSEA values $<.05$ are considered excellent $(<.08$ is acceptable), as are CFI and TLI values $>.95$ (> .90 is acceptable) [28].

\section{Results}

\section{Patients' perception of their caregivers' burden}

The comparisons made by the Student's t-test (paired measures) showed that patients underestimated their caregivers' scores for the dimensions ESTEEM (effect size: Cohen's $d=.364)$ and TIME $(d=.355)$. In addition, the Intraclass Correlation Coefficients (two-way mixed model, average measures, and absolute agreement) showed that the agreement between patients and their caregivers was moderate to good for all caregivers' burden dimensions, except TIME (Table 2).

Insert Table 2 about here

The emotional consequences, for both the caregiver and the patient, of their respective perception of the caregiver's burden were then tested (Model 1, Table 3). Most of this model fit indices were excellent: $\chi^{2}(72)=74.9$ (n.s.) $, \chi^{2} / d f=1.04, \quad R M S E A=.026, \quad C F I=.980$, $T L I=.975$ despite a rather high $\operatorname{SRMR}(.118)$. According to this model, it was mainly the deterioration in their own health that raised caregivers' emotional distress, while the perception that their caregiver could no longer manage their time raised patients' depression. Surprisingly, caregivers' financial difficulties were negatively linked to depression among both patients and caregivers. 
The Model 2 (Table 3) assessed the links between patients' overestimation of CB (patient's score minus caregiver's score to each burden subscale) and emotional distress among patients and their caregivers. This model again presented excellent fit indices: $\chi^{2}(15)=10.3$ (n.s.) $, \chi^{2} / d f=.69, R M S E A=.000, S R M R=.076, C F I=1.000, T L I=1.166$. It especially appeared that patients' underestimation of the deterioration in caregivers' health was linked to caregivers' anxiety.

Insert Table 3 about here

\section{Crossed views of patients and their caregivers concerning their emotional distress}

The means and standard deviations of emotional distress among patients and their caregivers, self-reported and proxy-reported, are given in Table 2. Anxiety scores were higher than or equal to 8 (sensitivity cut-off) for $73.3 \%$ of patients and $95.0 \%$ of caregivers. $71.7 \%$ of patients and $45.0 \%$ of caregivers had a depression score higher than or equal to 8. Student's $\mathrm{t}$-test revealed that caregivers were more anxious than patients, $t(59)=3.998, p<.001$, $d=.516$, while there was no significant difference regarding depression.

Caregivers overestimated patients' anxiety $(d=.272)$ and depression $(d=.513)$ while the latter correctly estimated caregivers' anxiety and depression. The ICC indicated a moderate to good agreement between patients and their caregivers regarding the emotional distress of them both, except for caregivers' anxiety which patients were not able to estimate adequately.

Structural equation modelling was used to assess the Actor-Partner Interdependence Model [30] in order to determine to what extent the distress experienced by the patient and their caregiver predicted the distress perceived in them by the other member of the dyad. It appeared that patients' anxiety is the only significant predictive factor of its perception by the caregivers $\left(\beta=.492, p<.001, R^{2}=.266, f^{2}=.362\right)$. Neither the patients' nor the caregivers' anxiety were significantly associated with the patients' perception of caregivers' anxiety. In contrast, the patients' perception of caregivers' depression was determined not only by the caregivers' actual depression $\left(\beta=.367, p<.001, R^{2}=.151, f^{2}=.178\right)$ but also by the patients' own depression $\left(\beta=.357, p<.001, \Delta R^{2}=.126, F(1,57)=10.130, p<.01\right)$. In the same way, the caregivers' perception of patients' depression depended not only on the patients' actual depression $\left(\beta=.566, p<.001, R^{2}=.343, f^{2}=.522\right)$ but also on the caregiver's own depression $\left(\beta=.261, p<.01, \Delta R^{2}=.067, F(1,57)=6.606, p<.05\right)$.

Predictive factors of the differences between patients' and caregivers' perceptions of burden and emotional distress 
Burden. Regarding the accuracy of patients' perception of their caregivers' burden, the fit indices of the Model 3 (Table 4) were quite acceptable: $\chi^{2}{ }_{(159)}=193.0, p=.034, \chi^{2} / d f=1.21$, $R M S E A=.060, S R M R=.095, C F I=.917, T L I=.891$. It especially appears that the better the patients' health (KARNOFSKY), the more they overestimated their caregivers' difficulties regarding time management.

Emotional distress. Misperception scores regarding emotional distress were computed so that a positive score represents an overestimation by an individual of the emotional distress of their relative. The fit indices of the Model 4 (Table 4) were acceptable: $\chi_{(139)}^{2}=162.7$, $p=.083, \chi^{2} / d f=1.17, R M S E A=.054, S R M R=.098, C F I=.942, T L I=.920$. It appeared that the assumed predictive factors did not actually account for the misperception of depression. Individuals with a higher level of education overestimated more their relatives' anxiety. Moreover, patients' anxiety was more overestimated by caregivers when patients are religious or when their families were less expressive.

Insert Table 4 about here

\section{Conclusions}

Previous studies conducted among dyads faced with chronic pain [21], amyotrophic lateral sclerosis [31], or stroke [20] reported significant and yet only weak to moderate correlations between CB and SPB. Globally, we found that patients had quite a good perception of their caregivers' burden even though patients were prone to overestimate their caregivers' difficulties (to manage their time especially) and underestimate their benefits (in terms of self-esteem), which means that SPB was globally higher than actual CB.

Nevertheless, this study also underlined that patients were not actually able to evaluate the difficulties their caregivers experienced to manage their time and carry on their own activities. Such difficulties were especially underestimated by patients whose health was deteriorated. Due to the attention and care required by patients, caregivers are actually deprived of some of their independence and freedom. They probably experience these constraints more systematically, rapidly, and intensely than the lack of social support, or health and financial difficulties, which may only occur subsequently. However, it is likely that, to protect patients' emotional state (especially when their health is deteriorated), caregivers hide from them their frustrations regarding their lack of time to live their own life. Indeed, the more patients perceived their caregivers were short of time, the more they reported depressive symptoms; 
and in line with previously reported data [10-12,19,20], feeling like a burden accounted for more than $20 \%$ of the variance of patients' depression scores. As a consequence, caregivers probably hide some of their daily difficulties to the patient in order to avoid distressing them. That may explain why our hypothesis that overestimation of CB by patients would be linked to their own emotional distress was not supported by data: patients probably do not know whether they overestimate CB or not. Nevertheless, as expected, underestimation by patients of CB triggered caregivers' emotional distress in addition to that caused by the burden itself, especially the lack of time and health impairments.

In line with the literature [32-35], caregivers were generally more anxious than patients and generally overestimated patients' emotional distress. As for patients, their estimations of their caregivers' anxiety were surprisingly based on clues which were neither linked to their caregivers' actual anxiety or their own one. This result is actually difficult to interpret and the ways palliative cancer patients' perceive their relatives' anxiety then remain to be studied. Anyway, the higher the education level of an individual, the more likely they were to perceive their relative as anxious. Indeed, the ability to perceive and distinguish accurately one's own emotional states and those of others depends on a person's educational level [36]. Besides, patients and caregivers were prone to confuse their own depressive feelings with that of the other member of the dyad. Expectedly, patients' distress was more overestimated by caregivers within families whose members rarely express their feelings. In contrast and in line with previous results [20], the perception accuracy of the other's experiences within the patient-caregiver dyad was not linked to whether patients and their caregivers were spouses or not, nor on differences in age or gender. At the end of a patient's life, the role of their natural caregivers seems to involve very specific processes of communication and support which may not depend on the social roles (spouse, parent, friend, etc.) the individuals may play outside of the context of the illness.

Together, our results suggest that patient-caregiver dyads have rather good but not accurate perceptions of their significant other's actual psychological state and needs for support. As expected, this lack of accuracy was linked somehow to emotional distress among both members of the dyad. Then, specific interventions should be developed to encourage communication among patient-caregiver dyads showing high levels of CB or SPB. They should constitute an opportunity for patients to tell their families they feel like a burden, and for caregivers to tell patients their difficulties in meeting patients' needs as well as their own [17,37]. They should also help dyads address issues regarding roles, expectations, preferences for support, and emotional reactions in order to reduce distress in both individuals [21]. 
Interventions should also involve revaluating patients by underlining the benefits their families gain by coming to their aid, especially gains of self-esteem which patients underestimated in our study, which may compensate in some ways the negative effects of caregivers' burden. Such interventions may improve each one's perceptions regarding the psychological, physical and social functioning of the other, and then lessen CB and SPB as well as their harmful consequences on quality of life and health.

The small size of our sample limited the possibility of taking the statistical analyses further, particularly to test more complex models taking into account the interactions between variables. Moreover, this study was cross-sectional, which did not allow us to account for changes in perceptions over time. Longitudinal studies should assess dyadic adjustments as care changes during the palliative process (depending on whether patients get hospitalised or get back home, the evolution of pain, autonomy, and general health...), as well as their effects on CB and SPB. Nevertheless, this study constitutes a first attempt to identify the risk factors of misperception regarding CB and distress within the patient-caregiver dyad. Further studies should keep on identifying these risk factors and assess especially the effects of coping strategies. Indeed, the perceptions of burden and distress in others intrinsically depend on how problems are managed and shared by the people faced with them: in this study, misperception was stronger among less expressive families who manage problems by holding back emotional information. A better identification of the factors involved in misperception would allow for a better targeting of the interventions proposed above for those dyads presenting high risk factors of distress.

\section{Acknowledgements}

The authors wish to extend their grateful thanks to all the participants of the study, as well as the staff of the Palliative Care Unit of the Centre Oscar Lambret for their invaluable assistance when gathering the data.

This work was supported by the Fondation d'entreprise TEVA.

The authors have declared no conflicts of interest.

\section{References}


1. Given BA, Given CW, Kozachik S. Family Support in Advanced Cancer. CA Cancer J Clin. 2001;51(4):213-31.

2. Glajchen $\mathbf{M}$. The emerging role and needs of family caregivers in cancer care. J Support Oncol. 2004;2(2):145-55.

3. Pitceathly C, Maguire P. The psychological impact of cancer on patients' partners and other key relatives. Eur J Cancer. 2003;39(11):1517-24.

4. Bevans M, Sternberg EM. Caregiving burden, stress, and health effects among family caregivers of adult cancer patients. JAMA J Am Med Assoc. 2012;307(4):398-403.

5. Given B, Wyatt G, Given C, Sherwood P, Gift A, DeVoss D, et al. Burden and Depression Among Caregivers of Patients With Cancer at the End of Life. Oncol Nurs Forum. 2004;31(6):1105-17.

6. Grov EK, Dahl AA, Moum T, Fosså SD. Anxiety, depression, and quality of life in caregivers of patients with cancer in late palliative phase. Ann Oncol. 2005;16(7):118591.

7. Higginson IJ, Gao W. Caregiver assessment of patients with advanced cancer: concordance with patients, effect of burden and positivity. Health Qual Life Outcomes. 2008 Jun 2;6(1):42.

8. Cousineau N, McDowell I, Hotz S, Hébert P. Measuring chronic patients' feelings of being a burden to their caregivers: development and preliminary validation of a scale. Med Care. 2003 Jan;41(1):110-8.

9. Van Orden KA, Witte TK, Cukrowicz KC, Braithwaite S, Selby EA, Joiner TE. The Interpersonal Theory of Suicide. Psychol Rev. 2010 Apr;117(2):575-600.

10. Chochinov HM, Kristjanson LJ, Hack TF, Hassard T, McClement S, Harlos M. Burden to others and the terminally ill. J Pain Symptom Manage. 2007;34(5):463-71.

11. McPherson CJ, Wilson KG, Murray MA. Feeling like a burden to others: a systematic review focusing on the end of life. Palliat Med. 2007;21(2):115-28.

12. Wilson KG, Curran D, McPherson CJ. A burden to others: a common source of distress for the terminally ill. Cogn Behav Ther. 2005;34(2):115-23.

13. Simmons LA. Self-perceived Burden in Cancer Patients. Cancer Nurs. 2007;30(5):40511.

14. Kishino M, Miyashita M. Self-perceived burden to family in terminally ill cancer patients at palliative care unit in Japan: perspectives of patients. BMJ Support Palliat Care. 2011;1(1):102-3. 
15. Winter L, Parks SM. The Reluctance to Burden Others as a Value in End-of-life Decision Making: A Source of Inaccuracy in Substituted Judgment. J Health Psychol. 2012 Mar 1;17(2):179-88.

16. Johnson JO, Sulmasy DP, Nolan MT. Patients' Experiences of Being a Burden on Family in Terminal Illness. J Hosp Palliat Nurs JHPN Off J Hosp Palliat Nurses Assoc. 2007 Sep;9(5):264-9.

17. Akazawa T, Akechi T, Morita T, Miyashita M, Sato K, Tsuneto S, et al. Self-Perceived Burden in Terminally Ill Cancer Patients: A Categorization of Care Strategies Based on Bereaved Family Members' Perspectives. J Pain Symptom Manage. 2010;40(2):224-34.

18. McPherson CJ, Wilson KG, Lobchuk MM, Brajtman S. Self-perceived burden to others: Patient and family caregiver correlates. J Palliat Care. 2007;23(3):135-42.

19. McPherson CJ, Wilson KG, Murray MA. Feeling like a burden: Exploring the perspectives of patients at the end of life. Soc Sci Med. 2007;64(2):417-27.

20. McPherson CJ, Wilson KG, Chyurlia L, Leclerc C. The balance of give and take in caregiver-partner relationships: An examination of self-perceived burden, relationship equity, and quality of life from the perspective of care recipients following stroke. Rehabil Psychol. 2010 May;55(2):194-203.

21. Kowal J, Wilson KG, McWilliams LA, Péloquin K, Duong D. Self-perceived burden in chronic pain: Relevance, prevalence, and predictors. PAIN®. 2012 Aug;153(8):173541.

22. Antoine P, Quandalle S, Christophe V. Vivre avec un proche malade : évaluation des dimensions positive et négative de l'expérience des aidants naturels. Ann Méd-Psychol Rev Psychiatr. 2010;168(4):273-82.

23. Hudson PL, Hayman-White K. Measuring the psychosocial characteristics of family caregivers of palliative care patients: psychometric properties of nine self-report instruments. J Pain Symptom Manage. 2006 Mar;31(3):215-28.

24. Razavi D, Delvaux N, Farvacques C, Robaye E. Validation de la version française du HADS dans une population de patients cancéreux hospitalisés. [Validation of the French version of the Hospital Anxiety and Depression Scale (HADS) in a population of hospitalized cancer patients.]. Rev Psychol Appliquée. 1989;39(4):295-307.

25. Untas A, Rascle N, Cosnefroy O, Borteyrou X, Saada Y, Koleck M. [Psychometric properties of the French adaptation of the Family Relationship Index (FRI)]. L'Encéphale. 2011;37(2):110-8. 
26. Schag CC, Heinrich RL, Ganz PA. Karnofsky performance status revisited: reliability, validity, and guidelines. J Clin Oncol Off J Am Soc Clin Oncol. 1984 Mar;2(3):187-93.

27. Keith RA, Granger CV, Hamilton BB, Sherwin FS. The functional independence measure: a new tool for rehabilitation. Adv Clin Rehabil. 1987;1:6-18.

28. Kline RB. Principles and Practice of Structural Equation Modeling. New York: Guilford Press; 2010. 445 p.

29. Tabachnick BG, Fidell LS. Using Multivariate Statistics. 6th ed. Boston: Pearson; 2012. $1024 \mathrm{p}$.

30. Cook W, Kenny D. The Actor-Partner Interdependence Model: A model of bidirectional effects in developmental studies. Int J Behav Dev. 2005;29(2):101-9.

31. Chiò A, Gauthier A, Calvo A, Ghiglione P, Mutani R. Caregiver burden and patients' perception of being a burden in ALS. Neurology. 2005;64(10):1780-2.

32. Sneeuw KCA, Sprangers MAG, Aaronson NK. The role of health care providers and significant others in evaluating the quality of life of patients with chronic disease. J Clin Epidemiol. 2002;55(11):1130-43.

33. Tang ST. Concordance of quality-of-life assessments between terminally ill cancer patients and their primary family caregivers in Taiwan. Cancer Nurs. 2006;29(1):49-57.

34. Tang ST, McCorkle R. Use of family proxies in quality of life research for cancer patients at the end of life: a literature review. Cancer Invest. 2002;20(7-8):1086-104.

35. Von Essen L. Proxy ratings of patient quality of life--factors related to patient-proxy agreement. Acta Oncol Stockh Swed. 2004;43(3):229-34.

36. Nandrino J-L, Baracca M, Antoine P, Paget V, Bydlowski S, Carton S. Level of emotional awareness in the general French population: effects of gender, age, and education level. Int J Psychol J Int Psychol. 2013;48(6):1072-9.

37. Lee JE, Shin DW, Cho J, Yang HK, Kim SY, Yoo HS, et al. Caregiver burden, patients' self-perceived burden, and preference for palliative care among cancer patients and caregivers. Psychooncology. 2015 Apr 1. 
Table 1. Characteristics of patients $(\mathrm{N}=60)$ and their caregivers $(\mathrm{N}=60)$.

\begin{tabular}{|c|c|c|}
\hline & Patient & Caregiver \\
\hline GENDER & 31 males, 29 females & 21 males, 39 females \\
\hline AGE: $M \pm S D[\operatorname{Min} ; \operatorname{Max}]$ & $63.2 \pm 12.2[35 ; 85]$ & $55.3 \pm 14.2[21 ; 86]$ \\
\hline $\begin{array}{l}\text { Marital status } \\
\text { Single } \\
\text { Married } \\
\text { Widowed } \\
\text { Divorced } \\
\text { Unmarried couple }\end{array}$ & $\begin{array}{r}\text { Missing data: } 1 \\
2 \% \\
69 \% \\
14 \% \\
8 \% \\
7 \%\end{array}$ & $\begin{array}{c}3 \% \\
74 \% \\
3 \% \\
5 \% \\
15 \%\end{array}$ \\
\hline $\begin{array}{l}\text { Socio-economic group } \\
\text { Self-employed } \\
\text { Employer, manager, higher professional } \\
\text { Lower professional, non-manual } \\
\text { Manual worker } \\
\text { Retired } \\
\text { Unoccupied }\end{array}$ & $\begin{array}{r}\text { Missing data: } 1 \\
2 \% \\
13 \% \\
12 \% \\
5 \% \\
63 \% \\
5 \%\end{array}$ & $\begin{array}{r}\text { Missing data: } 1 \\
3 \% \\
15 \% \\
20 \% \\
2 \% \\
43 \% \\
17 \%\end{array}$ \\
\hline $\begin{array}{l}\text { Level of EDUCATION } \\
1 \text { - Primary } \\
2 \text { - Junior general secondary education } \\
3 \text { - Vocational secondary education } \\
4 \text { - Senior general secondary education } \\
5 \text { - College education }\end{array}$ & $\begin{array}{r}\text { Missing data: } 1 \\
12 \% \\
20 \% \\
29 \% \\
12 \% \\
27 \%\end{array}$ & $\begin{array}{r}\text { Missing data: } 1 \\
20 \% \\
19 \% \\
20 \% \\
17 \% \\
24 \%\end{array}$ \\
\hline $\begin{array}{c}\text { RELIGIOSITY } \\
\text { Yes } \\
\text { No }\end{array}$ & $\begin{array}{r}\text { Missing data: } 6 \\
81 \% \\
19 \%\end{array}$ & $\begin{array}{r}\text { Missing data: } 3 \\
65 \% \\
35 \%\end{array}$ \\
\hline $\begin{array}{l}\text { Primary tumour location } \\
\text { Breast } \\
\text { Upper aero-digestive tract } \\
\text { Colorectal } \\
\text { Unknown primary location } \\
\text { Sarcoma } \\
\text { Others }\end{array}$ & $\begin{array}{l}17 \% \\
15 \% \\
10 \% \\
10 \% \\
8 \% \\
40 \%\end{array}$ & \\
\hline $\begin{array}{c}\text { KARNOFSKY } \\
80-100 \\
50-70 \\
20-40\end{array}$ & $\begin{array}{l}10 \% \\
47 \% \\
43 \%\end{array}$ & \\
\hline $\begin{array}{l}\text { AUTONOMY } \\
\begin{array}{l}110-126 \\
90-109 \\
70-89 \\
48-69\end{array}\end{array}$ & $\begin{array}{l}25 \% \\
23 \% \\
22 \% \\
30 \%\end{array}$ & \\
\hline $\begin{array}{l}\text { HOME HOSPITALISATION } \\
\text { Yes } \\
\text { No }\end{array}$ & $\begin{array}{r}\text { Missing data: } 7 \\
47 \% \\
53 \%\end{array}$ & \\
\hline
\end{tabular}


Table 2. Means and Standard Deviations for each subscale of the CRA and the HADS among patients $(N=60)$ and their caregivers $(N=60)$.

\begin{tabular}{lllll}
\hline & $\begin{array}{l}\text { Caregiver's } \\
\text { perception }\end{array}$ & $\begin{array}{l}\text { Patient's } \\
\text { perception }\end{array}$ & $t(59)$ & ICC \\
& $M \pm S D$ & $M \pm S D$ & & \\
\hline ESTEEM & $4.23 \pm .47$ & $4.02 \pm .57$ & $2.817^{* *}$ & $.540^{* * *}$ \\
TIME & $3.82 \pm .82$ & $3.42 \pm .81$ & $2.749 * *$ & .077 \\
SUPPORT & $2.21 \pm 1.05$ & $2.33 \pm .99$ & -.929 & $.709 * * *$ \\
HEALTH & $2.85 \pm .92$ & $2.68 \pm .89$ & 1.240 & $.507 * *$ \\
MoNEY & $2.52 \pm .92$ & $2.30 \pm 1.00$ & 1.859 & $.691^{* * *}$ \\
\hline Patient's anxiety & $11.35 \pm 3.31$ & $10.42 \pm 3.60$ & $2.105 *$ & $.667 * * *$ \\
Patient's depression & $11.45 \pm 4.13$ & $9.47 \pm 4.44$ & $3.971 * * *$ & $.701^{* * *}$ \\
Caregiver's anxiety & $12.64 \pm 3.07$ & $13.54 \pm 2.88$ & -1.714 & .121 \\
Caregiver's depression & $8.24 \pm 4.70$ & $8.12 \pm 3.49$ & .194 & $.565^{* * *}$ \\
\hline
\end{tabular}

Note: $* p<.05 ; * * p<.01 ; * * * p<.001$. ESTEEM indicates a positive impact while the other CRA subscales indicate negative consequences. 
Table 3. Links between the patient's and their caregiver's perceptions of CB and their own experienced emotional distress $(\mathrm{N}=60)$.

\begin{tabular}{|c|c|c|c|c|}
\hline & $\begin{array}{c}\text { CAREGIVER'S } \\
\text { ANXIETY }\end{array}$ & $\begin{array}{l}\text { CAREGIVER'S } \\
\text { DEPRESSION }\end{array}$ & $\begin{array}{l}\text { PATIENT'S } \\
\text { ANXIETY }\end{array}$ & $\begin{array}{c}\text { PATIENT'S } \\
\text { DEPRESSION }\end{array}$ \\
\hline \multicolumn{5}{|l|}{ Model 1} \\
\hline \multicolumn{5}{|l|}{ CAREGIVER'S PERCEPTION OF ESTEEM } \\
\hline CAREGIVER'S PERCEPTION OF TIME & .116 & .094 & & \\
\hline \multicolumn{5}{|l|}{ CAREGIVER'S PERCEPTION OF SUPPORT } \\
\hline CAREGIVER'S PERCEPTION OF HEALTH & $.353 * *$ & $.410 * * *$ & & \\
\hline CAREGIVER'S PERCEPTION OF MONEY & & $-.225 *$ & & \\
\hline \multicolumn{5}{|l|}{ PATIENT'S PERCEPTION OF ESTEEM } \\
\hline PATIENT'S PERCEPTION OF TIME & & & & $.389 * * *$ \\
\hline \multicolumn{5}{|l|}{ PATIENT'S PERCEPTION OF SUPPORT } \\
\hline PATIENT'S PERCEPTION OF HEALTH & & & & .088 \\
\hline PATIENT'S PERCEPTION OF MONEY & & & & $-.231 *$ \\
\hline$R^{2}$ (Effect size: Cohen's $f^{2}$ ) & $.173(.209)$ & $.260(.351)$ & & $.213(.271)$ \\
\hline \multicolumn{5}{|l|}{ Model 2} \\
\hline \multicolumn{5}{|l|}{ PATIENT'S OVERESTIMATION OF ESTEEM } \\
\hline PATIENT'S OVERESTIMATION OF TIME & -.143 & -.149 & & \\
\hline \multicolumn{5}{|l|}{ PATIENT'S OVERESTIMATION OF SUPPORT } \\
\hline PATIENT'S OVERESTIMATION OF HEALTH & $-.281 *$ & -.213 & & \\
\hline \multicolumn{5}{|l|}{ PATIENT'S OVERESTIMATION OF MONEY } \\
\hline$R^{2}\left(\right.$ Effect size: Cohen's $\left.f^{2}\right)$ & $.128(.147)$ & $.090(.099)$ & & \\
\hline
\end{tabular}

Notes: This table only displays the standardised regression weights for actually tested paths.

$* p<.05 ; * * p<.01 ; * * * p<.001$. 
Table 4. Predictive factors of the differences between the perceptions of burden and emotional distress by patients and their caregivers $(\mathrm{N}=60)$.

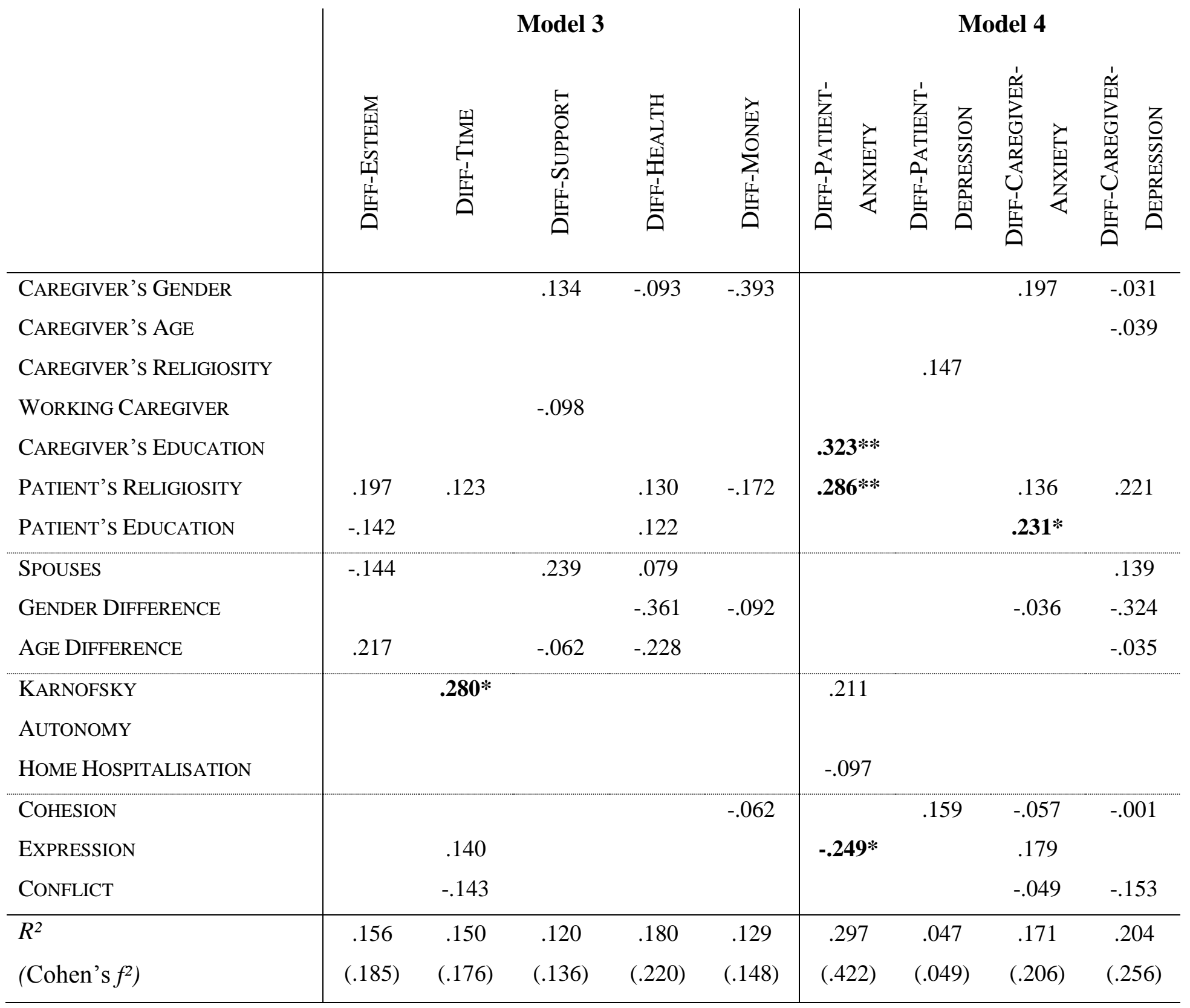

Notes: This table only displays the standardised regression weights for actually tested paths.

$* p<.05 ; * * p<.01$. 